\title{
ACTION RESEARCH IN WASTE MANAGEMENT: APPLICATION TO CONSTRUCTION AND DEMOLITION WASTE IN THE STOCKHOLM REGION
}

\author{
Graham Aid \\ Nils Brandt \\ Division of Industrial Ecology, Royal Institute of Technology (KTH) \\ Stockholm, Sweden
}

\begin{abstract}
The action research methodology and several of its methods have previously been highlighted and described by the authors as a fitting and rigorous framework approach for complex waste management systems. This was in response to criticism of the ex ante selection of traditional empiric systems analysis tools to provide decision support and 'sustainable improvement' in such complex systems which often involve strong human and political factors. Several of the action research methods described have recently been utilized in a case study around mineral (aggregate) construction and demolition waste in the Stockholm region. These methods were integrated through a series of workshops and work areas undergone together with project members from several private and public sectors. Leaving the problem fuzzy (loosely defined) in the beginning; utilizing convergent interviewing, rich pictures and focus groups allowed the researchers and partner stakeholders to identify not one but several problem areas within the system of focus. Indicator creation and a dialectic processes were then used to identify qualitative and quantitative aspects of salience around these problem areas. These resulting indicators were strengthened through a process of verification. Each indicator was then analyzed by what was deemed to be appropriate and transparent means. It is argued that this approach may create better communication, transparency, and understanding by the stakeholders. These factors in turn allowing stronger stakeholder ownership of the process and assisting in more informed decisions and help to provide stability for desired change. However the process was not without its drawbacks such as intense communication and time requirements.
\end{abstract}

\section{KEYWORDS:}

waste management; action research; systems analysis; decision support; facilitation; soft systems methodology 


\section{INTRODUCTION}

An action research (AR) project was commenced in the fall of 2009 after both top down policy and bottom up (industrial) concern highlighted construction and demolition (C\&D) waste to be a waste system necessitating substantial changes. Project "BRA" ("bygg-och rivningsavfall" is Swedish for "construction and demolition waste"), which focuses on the Stockholm region, kicked off its first workshop in November of 2009 and is active to date (autumn, 2010). Top down driving forces came from both the European Union and Sweden. The new European Waste Directive's goal to recycle or reuse $70 \%$ of nonhazardous C\&D waste (by weight) by 2020 has given member states a lofty task for the next decade [1]. Sweden's own Environmental Objectives (Miljömål) also set ambitious goals for a "good built environment" that aim to reduce the use of natural aggregates, improve the logistics of aggregate floods, and increase the recycling of materials [2]. Concerns have been cropping up from the industry side as traditional markets for inert C\&D materials (landfills and landfill cover) are rapidly closing in Sweden. Many industry actors have shown interest in catalysing markets for "higher use" applications of inert C\&D waste. After consultation with project participants previous to and during the first workshop it was agreed to focus on the inert (aggregate) fractions within C\&D waste such as concrete, asphalt, and bricks. This is due to the fact that other C\&D waste materials such as paper, plastic, wood, and insulation already have well established, higher value use, recycling paths away from the landfill in the region [3].

The annual amount of inert (mineral) waste (excluding dirt) arising from construction and demolition activities within Sweden is reported to range from 2.3 million (in 2004) and 7 million (in 2006) tons [4]. These statistics are believed to be highly uncertain by project BRA members, who estimate that numbers could be several times higher [5]. In any case project members have agreed to attempt to improve the reliability and usability of statistics around these types of materials within the project. It was also agreed by project members during the pre-study phase and first workshop that it would be very difficult for a single actor to influence large systems changes and that a multi-stakeholder process would be beneficial to catalyse change. The initial focus and problem definition of the project was kept open and "fuzzy" in an attempt to let the stakeholders steer this direction after their mutual (and yet multifarious) perceptions of the system. As is later shown, this presented some interesting results that would have been difficult to formulate from the start.

\section{AIM}

This article is intended as a presentation and critical review of the action reserach methodology applied to a complex waste management system. The review seeks to both present the findings of the case to date as well as to review the strengths and weaknesses of the methodology applied within such a context. 


\section{STRUCTURE OF THE PROJECT}

Project BRA synthesized parts of Soft Systems Analysis [6] in the early procedures along with methods from Bell and Morse [7] regarding indicator creation and analysis. The general flow of the project structure can be seen in Figure 1.

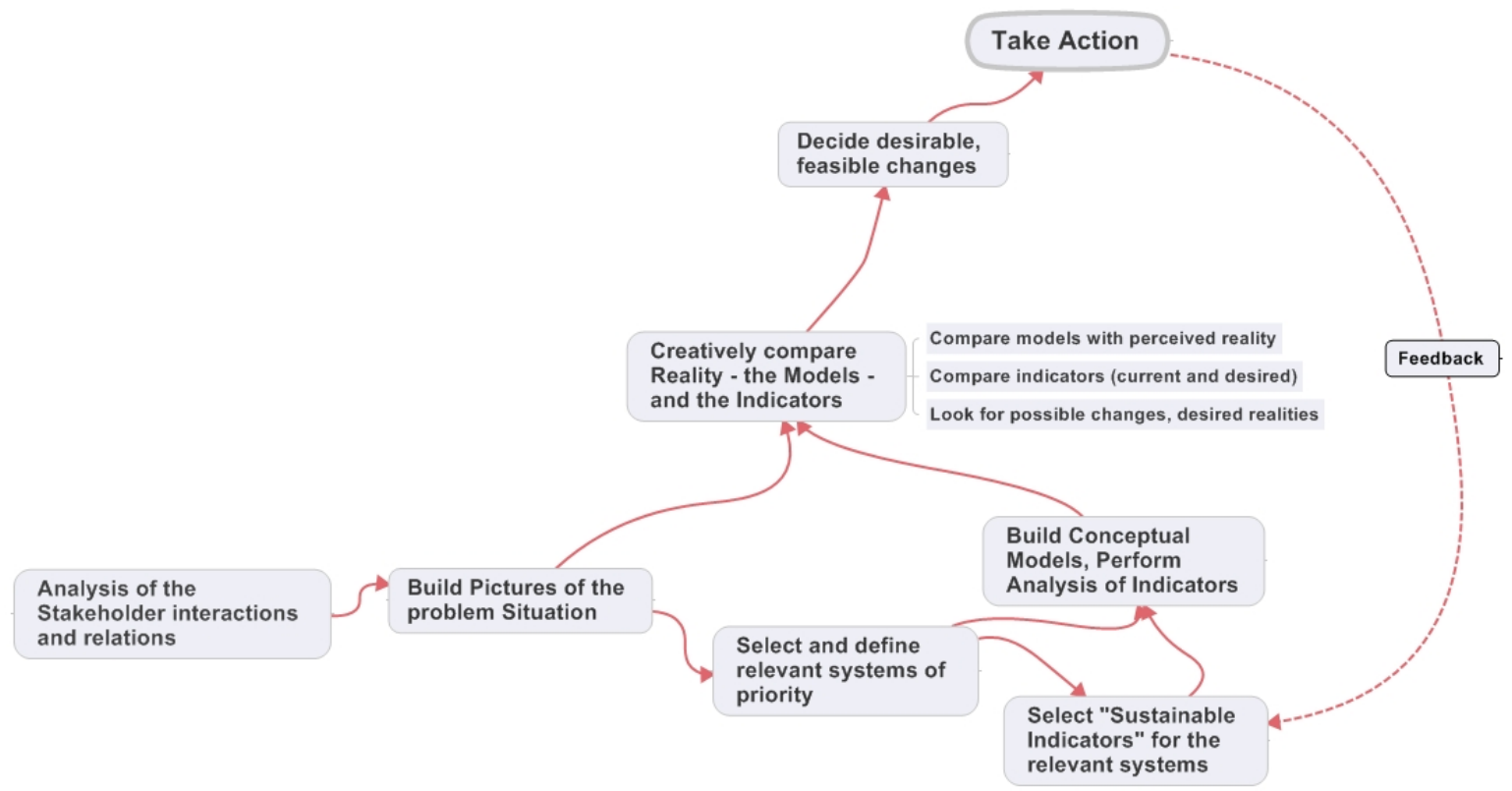

Figure 1 - The general project BRA diagram

Initially the project was left very "fuzzy", (less precise) as shown in Figure 2. This allowed for less influence from what the researchers initially believed to be the problem, and more input of the multiple actors into the formulation of the system, problems and issues of salience.

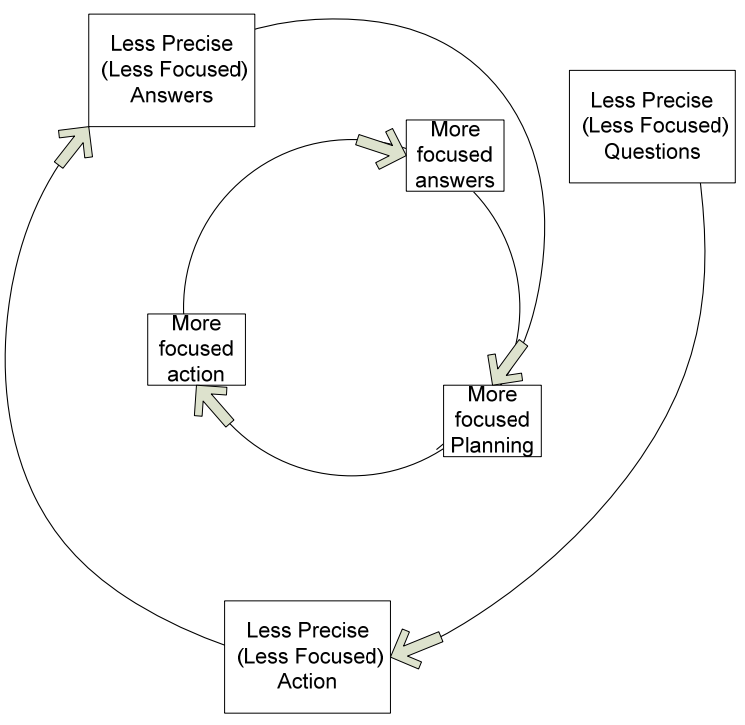

Figure 2 - The general progression of an action research project 
After analysis of the current status of selected indicators, scenario analysis and "backcasting" (tools used within the last three steps in Figure 1) are used to visualize paths toward project defined goals. Action is then taken from what are considered to be desirable, reasonable and doable (under resource constraints). Figure 1 could is enriched by adding an information "feedback" flow from the action and the measurement of indicators. This feedback flow is clarified in Figure 3, which many may recognise as stemming the "Snyder" process, or total quality management [8]. Figure 3 is essentially a complimentary (and more linear) perspective to the project framework in Figure 1.

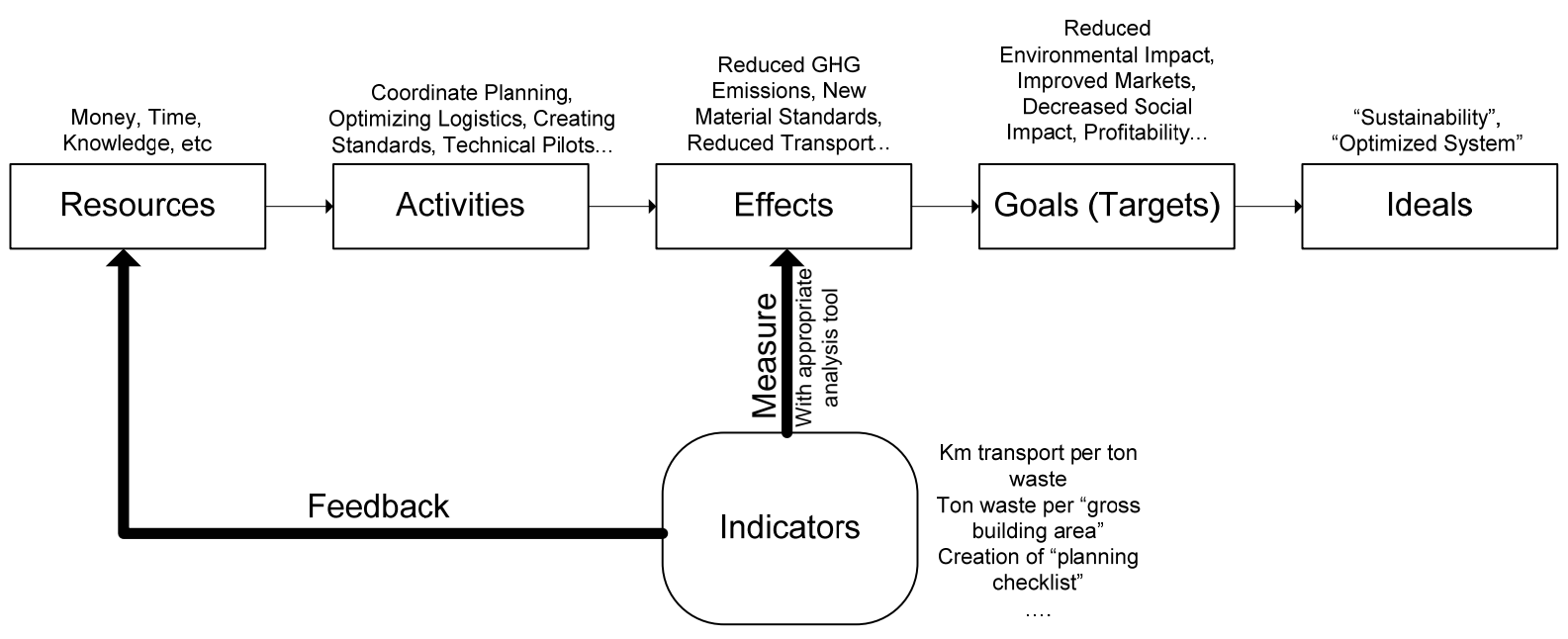

Figure 3 - An adapted "Snyder Process" illustrating the use of indicators and feedback in a systems model (adapted from Dick 2006) (details from Project BRA)

This is by no means the only framework for an action research project, but what was decided to fit the situation at hand. It is the authors' belief that tools should be chosen and arranged as appropriate to the situation at hand. More specifics about the action research methodology and its methods in the context of waste management can be found in the authors' methodology paper (currently under review) titled "Action Research for Waste Management: Benefits and challenges of applying critical theory to complex systems" [9].

\section{PRESTUDY}

In the fall of 2009, a questionnaire concerning stakeholder interests and system problems was sent out to 20 potential project participants after the initial (top down and bottom up) drivers arose. The response rate was not high, with only 5 of the stakeholders filling in the online [10] form. A much better response was achieved through direct telephone contact, and subsequential face to face informal interviews with 5 of the initial stakeholders. It was from these informal interviews that contacts were gained and the groundwork was laid for the first workshop.

\section{WORKSHOP I}


The kickoff workshop for the project was quite positive with 10 participants actively working to clarify the system of focus, the problems within, and the salient areas upon which to set resources (money, time, energy). First the stakeholders perspectives of what a construction and demolition waste system included were broadened though the creation of "rich pictures" in three breakout groups. Rich pictures (which are used to naturally map out a system, its actors, relationships, material flows, information flows, conflicts, etc) are explained in detail by Checkland [6]. Although space and confidentiality limits our ability to share these pictures, they effectively led to several outcomes:

- The participants were able to clarify the system of focus

- Various new perspectives were able to broaden the participants understanding of how the system works

- Several problem areas were identified

- Potential improvements were highlighted

- New actors were identified

- Areas of salience began to arise

- Actors freely discussed their experience through the aid of the images

- Correlations between problems and various issues were identified

Some of the "system's actors" whom were identified were from the areas of:

- Building and Construction

- Demolition

- Facility contractors (such as the housing authorities, private housing companies, etc)

- Waste management

- Regional authorities (municipality, county, regional planning office)

- Transportation

- The mining \& stone industry

- Consultants (architects, logistics, etc)

- Research institutes (KTH, Cement and Concrete Institute -CBI, etc)

- Forums (Construction forums, Housing forums, etc)

- The roads administration (vägverket)

In focus group sessions that followed (using the rich pictures as aides) a list of problem areas was produced. This list included:

- The price for recycled materials (often nonexistent)

- Competition from cheap substitute material arising from infrastructure (tunnel) projects in the region

- Taxes (or lack of when regarding the covering of landfills)

- Quality of recycled products

- The lack of common recycled product standards

- Clients' attitudes and expectations

- Coordination between the actors (on key issues such as logistics or pre-planning)

- Environmental impacts

- Workplace environment and safety

- Transportation inefficiency

- Lack of local or regional temporaty storage

- Time restrictions (when needing the select new material) 
- Legislations (restricting the reuse of such materials or promoting the use of virgin materials)

- A cumbersome and difficult to apply waste definition

The participants then prioritized five areas of focus through a two phase voting procedure. First all participants were allowed to choose what they believed to be the five most important "areas" to set recourses and time on when performing further analysis. These lists were tallied and the top ten (most votes) were written up. Participants then voted again in a second round, where choices were limited to the top ten that were written up. The resulting focus areas were:

- Environment

- Economy

- Coordination (including planning and logistics)

- Product (Technical, Classification, Standardization)

- Statistics

If this participative process had not been performed, the academic analysis of the system would definitely have had a different (and most probably more narrow) prioritization. It is common for systems analysts to focus on technical optimization, environmental optimization, and even economic optimization; but other areas such as highlighted here can be overlooked and eventually hinder change implementation. For example, a technology could be shown to be environmentally and economically superior under systems analysis, but if well known standards are missing or if the coordination is poor, implementation of improved practices may not be feasible.

\section{WORKSHOP II}

The second workshop within the series was also positive in expanding the participant's knowledge and in acquiring a list of sustainability indicators to measure. The participants built upon the progress of the kickoff workshop and came together with the goal to further their understanding of the system and their strategy to improve the prioritized areas. The workshop began with several inspirational presentations, such as one by the Dutch C\&D recycling organization.

After this "state of the issue" session the participants laid the groundwork for their focus group deliberations by further clarifying the system of concern using the CATWOE tool from soft systems analysis, where the "customers, actors, transformation process, world view, owner, and environmental constraints" were identified [6]. The results of this activity are available online [11]. Following this focusing activity, participants began their work on the creation of "sustainable indicators". The participants had quite an active discussion in two separate focus groups for two hours. Their discussions, using the "areas of priority" for focus, were recorded, transcribed, and translated (at a later time). All participants then collectively reviewed the preliminary list of 42 indicators [12]. The distillation to a short list of the most useful, easily measurable, and understandable indicators proved to be a very difficult task. A two phase voting procedure such as used in the first workshop was attempted, but felt cumbersome. In the last deliberations of the workshop, a list of eight (raw) indicators was agreed upon [12], and it was acknowledged that these indicators would need to be clarified before analysis tools could be selected (also time ran short for this final activity). 


\section{FOLLOW UP INTERVIEWS}

10 follow-up "convergent" interviews were performed after the second workshop. While structured to allow for the stakeholders general ideas and concerns to take priority, a good amount of the focus generally landed on the fine tuning of the group's indicators. After all interviews the indicator list shown in Table 1 was finished.

8

\begin{tabular}{|c|c|c|}
\hline & Focus Area & Indicator \\
\hline $1 \mathrm{a}$ & $\begin{array}{l}\text { Climate Impact and } \\
\text { Transport System }\end{array}$ & $\mathrm{km} /$ ton waste \\
\hline $1 \mathrm{~b}$ & "'" & ton waste/truck \\
\hline 2 & Climate Impact & $\mathrm{C}_{2} 2$ equivalent exhaust/ton recycled product (per product) \\
\hline 3 & Use of Resources & Sorting grade ( $\%$ sorted/total weight) \\
\hline 4 & "'" & Waste effectivity (ton waste/Gross Area - leaving the gates) \\
\hline 5 & Market & SEK/ton $\downarrow$ \\
\hline $5 \mathrm{a}$ & """ & Clean (source sorted) concrete \\
\hline $5 b$ & "'" & Low grade concrete \\
\hline $5 \mathrm{c}$ & "" & "Packable" 0-30 \\
\hline $5 \mathrm{~d}$ & "'"' & "Recycled" 0-63 \\
\hline $5 \mathrm{e}$ & "" & Recycled Asphalt 0-16 \\
\hline 6 & "" & To establish "well known and used" material standards \\
\hline 7 & Planning & $\begin{array}{l}\text { Prepare a checklist for "coordinated planning for reuse and } \\
\text { recycling" }\end{array}$ \\
\hline 8 & $\begin{array}{l}\text { Social environmental related } \\
\text { health }\end{array}$ & Noise from chrushing on location \\
\hline
\end{tabular}

Table 1 - Project Bra Indicator List as of July 2010

As can be seen, the areas of focus for the final indicators were slightly altered from the original areas of focus. In the interviews a large emphasis was placed on the need for indicators $1 \mathrm{a} \& \mathrm{~b}$ and 7 . $1 \mathrm{a}$ and $\mathrm{b}$ will be used when working on the optimization of material logistics. Indicator 2 will be used in addition to substitute product data for screening LCA comparisons. Indicator 3 is a common measurement within the building industry to measure their efficiency in source sorting. It is noted that high sorting combined with less waste per truck could result in less than optimal results. Indicator 4 is intended to measure the reduction of waste as well as the increase of reuse on location. It is good to keep in mind that (possibly highly efficient) processing/recycling at a nearby facility will not be shown by this indicator. The product prices in 5a-5e are those currently on the Stockholm market, but new materials could be included as identified. Indicator 6 , regarding standards, is being approached by attempting to place materials in current construction material purchasing decision and standard databases (such as byggvarubedomningen.se). Indicator 7 is being worked on by a project group headed by the building sector. This indicator is important as substantial preplanning is required to test, permit, to find temporary storage for the material, etc, if material is to be reused on location. Indicator 8 was brought up in the interviews as an aspect that would be especially essential to control if upgrading on location is to be attempted and will compared to normal noise levels for building permits.

\section{FUTURE WORK}


As is shown in Figure 1, there are still several steps to be performed within the project. In the end of October 2010, Workshop III will be held where the current state of indicators will be presented. After this presentation, desirable (and realistic) levels for these indicators will be produced. It is also at this event that stakeholders will begin their work on envisioning pathways to achieve these future levels. This workshop will include several stakeholders from the top down side, who are interested in including suggestions from the project in the regional and national waste plans.

A further workshop will be held a few months after Workshop III where a more complete scenario analysis and backcasting will be performed, as well the establishment of feedback mechanisms and sub project routines. It is hoped that full ownership of the projects further work can be taken over by the stakeholders from this point.

\section{DISCUSSION}

\subsection{Discussions concerning project BRA}

Up until this point the overall project seems to be providing positive feedback and general progress, however this should be verified through more official feedback mechanisms (other than just side discussion) such as process review questionnaires. Some other issues identified that need further development were the processes of indicator selection and voting. It is possible that the use of a "logframe" [7] approach to analyzing the indicator candidates could assist in easing this process. Other suggestions to ease this problem are given by Bob Dick in his document on "Information sharing using voting" [13].

The restriction of project members to a smaller number of industrial stakeholders in the first workshop is seen as being a beneficial choice as it provided participant comfort and a "grassroots" feeling to the start of the work. The stakeholders then later decided to bring in the top down actors after some clarification of the scope of the work was in place.

It needs to be emphasized that for the indicators to work toward what the group believes to be sustainable improvement, it first needs to be established that increased reuse and recycling is indeed an improvement over the current practice (and how much of an improvement this would be). Therefore not all the indicator's are not of initial salience, but of first focus are the indicators aimed at improving knowledge of the system, and focus is expected to shift later the indicators geared toward promoting system changes.

Recording the workshop's audio was useful, especially as source material to identify "arising agreement" and to seek disagreement in later project activities (such as interviews). This method of critical reflection (explained more in [9] is expected to add to the rigour of the process.

It is also interesting to note that similar outcomes and areas of importance were achieved from two very different approaches to construction and demolition waste management; AR and a matrix based (weighted) formative scenario methodology developed by Spoerri et al .[14.] Both processes use various sources for identifying areas of salience. Spoerri and his colleagues used a sophisticated matrix for evaluating interactions and scenarios. BRA used looser focus groups, scenarios and backcasting without trying to weight or quantify all the systems aspects. 


\subsection{Discussions concerning the application of AR and its methods to waste management situations}

As is discussed around many AR projects, the methodology requires plenty of time input by the facilitator. Much time is needed to plan and create agendas, approach participants, structure participative activities, review the activities (through recordings or interviews), update project information (through websites and emails), promotion, etc. This could all amount to weeks or months of work if performed by only one facilitator. However this layout of time could reasonably be justified if the methodology creates more valuable outcomes, such as greater stakeholder knowledge and system improvements, than that of weeks or months spent on (possibly too) thorough empiric system analysis. In other words, the extra layout of time in order to make the process more communicative and participative may in turn save more time from being spent on mal-focused or overly deep systems analysis. In contrast, AR could also be overdone and mal-focused, especially when trying to appease all stakeholders' interests. A balance between appease and action might have to be sought.

The facilitator's time is definitely not the only time being consumed, and an effort to make the process worthwhile for all participants is clearly required. This can be addressed by keeping stakeholder's requirements and stakeholder's development high on the agenda. Additionally, making the process of data collection and analysis as simple (often using already in place routines) is appreciated by project participants. Well structured processes and highlighting project benefits also help to reinforce the time input by participants.

\section{CONCLUSIONS}

Through this article an interim report of the collaborative project "BRA" was presented to display the practical application of AR for waste management. It is the authors' belief that some of the systems issues left to the side by other (more empiric) methodologies may be more thoroughly addressed through this method. However this is not without its drawbacks, especially those of time and communication requirements. 


\section{ACKNOWLEDGEMENTS}

The authors' would expecially like to thank the various participants in the project for placing their trust and time in this action research project. Many thanks are also due to Monica Olsson and David Lazarević for their steady input, good humour, and support to the project formation, development and administration.

\section{REFRENCES}

[1] European Commission, 2008. European Directive 2008/98/EC of 19 November 2008 on waste and repealing certain Directives. EC

[2] Swedish Environmental Objectives Council, 2007. Sweden's environmental objectives In an interdependent world de Facto 2007

[3] Aid, G., 2008, Potential Technology for the Advanced Utilization of Construction, Demolition and Industrial Waste: From the Context of the EDAB Partnership's Niche. Stockholm: Skolan för industriell teknik och management,Kungliga Tekniska högskolan.

[4] The Swedish EPA (Naturvårdsverket) 2008. Avfall i Sverige 2006. ISBN:978-91-6205868-5

[5] Project BRA, 2009. Workshop 1 Tapes. Industrial Ecology Archives

[6] Checkland, P., 1999. Systems Thinking, Systems Practice: Includes a 30-Year Retrospective. Wiley.

[7] Bell, S. and Morse, S., 2008. Sustainability Indicators: Measuring the Immeasurable. Revised and Updated. Earthscan Publications Ltd.

[8] Dick, B., 2006. The Snyder evaluation process [On line]. Available at http://www.uqconnect.net/action_research/arp/snyder.html

[9] Aid, G., Brandt, N., 2010. Action Research for Waste Management: Benefits and challenges of applying critical theory to complex systems (Currently under review)

[10] Project BRA, 2009. "Initial Questionairre" [On line]. available at: http://www.framtidstank.com/projekt/BRA/Arbete/questionnaire

[11] Project BRA, 2010. CATWOE, [On line]. available at: http://projektbra.blogspot.com/2010/03/catwoe-system-clarification.html

[12] Project BRA, 2010. Initial indicator list, [On line]. available at: http://projektbra.blogspot.com/2010/03/preliminart-list-alla-forslag.html

[13] Dick, B., 1997. Information sharing through voting [On line]. Available at: http://www.scu.edu.au/schools/gcm/ar/arp/voting.html

[14] Spoerri, A., Lang, D., Binder, C., and Scholz, R., 2009. Expertbased scenarios for strategic waste and resource management planning--C\&D waste recycling in the Canton of Zurich, Switzerland. Resources, Conservation and Recycling 53, no. 10 (August): 592-600. doi:10.1016/j.resconrec.2009.04.011. 